\title{
ANÁLISE DA PERCEPÇÃO DOS COLABORADORES SOBRE A IMPLANTAÇÃO DA MANUFATURA ENXUTA NA PRODUÇÃO DE CHINELOS
}

\author{
Carlos Roberto Franzini Filho (UAM) crfilho@anhembi.br \\ Omar Ahmed Abbas omar_abbas27@hotmail.com \\ Thayná Nafis Peres Bellini Caldeira (UAM) thayna.caldeira@ hotmail.com \\ Maria dos Remédios Sousa Silva (UAM) sousamaria.mss@ gmail.com \\ Carinna Taborda Moreira (UAM) carinna.taborda@gmail.com
}

\section{Resumo}

A indústria calçadista é um setor que passou a enfrenta acirrada competição de produtos estrangeiros. Em um estudo realizado em 2016 pelo Instituto de Estudos e Marketing Industrial (IEMI), mostrou que o Brasil era o quarto maior produtor de calçados em geral do mundo, atrás apenas de países como China, Índia e Vietnã. No Brasil, dos 935 milhões de calçados produzidos, 34\% correspondem a produção de chinelo de borracha, movimentando cerca de 4,3 bilhões de reais na economia nacional. Esse novo cenário vem obrigando as empresas nacionais a promoverem uma grande mudança nos seus processos produtivos e administrativos. O presente artigo tem por objetivo apresentar os principais aspectos relacionados a implementação do Lean Manufacturing na fabricação de chinelos. Para atingir o objetivo proposto, realizou-se um estudo de caso que aponta para a percepção dos funcionários quanto às competências técnicas e sociocomportamentais na implementação do Lean Manufacturing. Os resultados demonstram a capacidade de implementação neste ambiente, assim como a percepção dos colaboradores para a aplicação da filosofia.

Palavras-Chaves: Produção de chinelos, Lean Manufacturing, Gestão da Produção e Operações, Competências técnicas e comportamentais. 


\section{Introdução}

A indústria calçadista é uma das mais antigas do mundo. Não é difícil imaginar que ainda na idade antiga, ou mesmo na pré-história, o ser humano já utilizava formas rudimentares de calçados e eventualmente fazia da confecção desses itens uma forma de negócio, ainda que primitiva. Desde então os calçados experimentaram grande evolução na variedade de formatos e materiais.

Um dos principais calçados utilizados por muitas pessoas é o chinelo de borracha, mais conhecido como havaianas. O primeiro par surgiu em 1962, inspirado nos chinelos de dedo japoneses tradicionais chamados Zori, feitos de palha de arroz.

Com a produção em larga escala deste tipo de calçado e o cenário competitivo para este segmento, as empresas têm sido pressionadas a desenvolverem processos inovadores para alcançar a satisfação e a fidelização dos seus clientes. Essas organizações convivem com ambiente complexo e de rápidas mudanças, sendo obrigadas a oferecerem cada vez mais produtos e serviços customizados e dependem de um fluxo de informações preciso e pontual, de processos eficientes e eficazes para manterem um desempenho competitivo no curto prazo e uma base de conhecimento sólida para enfrentar e sobreviver.

O Lean Manufacturing (Manufatura enxuta) é uma das metodologias que vem sendo utilizada nas empresas para promover melhorias e reduzir desperdícios no chão de fábrica desde a década de 70. A aplicação dos conceitos Lean é muito comum na manufatura, pois é neste campo que se observam os maiores índices de agregação de valor (HINES, 2000).

Slack (2002) salienta que a implementação do Lean Manufacturing é focado em obter as coisas certas no lugar certo, na hora certa, na quantidade certa para atingir o fluxo de trabalho perfeito, minimizando falhas e tornando flexível e capaz de mudar. Estes conceitos de flexibilidade e mudança são principalmente necessários para permitir o nivelamento da produção (Heijunka). Mais importante, todos esses conceitos têm que ser compreendido, apreciado, e abraçado pelos funcionários que fabricam os produtos e, portanto, desenvolvem os processos que entregam o valor.

A partir das considerações iniciais, este trabalho propõe-se a analisar a percepção dos colaboradores quanto as competências técnicas e comportamentais para a implementação do Lean Manufacturing no processo produtivo de chinelos 


\section{Referencial teórico}

A seguir está apresentado o referencial teórico quanto ao processo produtivo do chinelo e manufatura enxuta.

\subsection{Processo produtivo do chinelo}

Acredita-se que os chinelos, as sandálias mais simples, tenham se originado no Egito Antigo por volta de 4.000 A.C. Eles apareceram em murais que mostravam desenhos incrustados de joias sendo usados pelos faraós. O mais antigo chinelo/sandália sobrevivente está atualmente em exibição no Museu Britânico de cerca de 1.500 A.C. Com o tempo, os materiais usados para fazer chinelos mudaram de papiro, folhas de palmeira e palha para plástico e borracha (INDEPENDENT, 2010).

De acordo com Transparency Market Reserch (2018), o chinelo surgiu na cultura ocidental após a Segunda Guerra Mundial, quando a produção de borracha era alta no Japão. Durante a década de 1950, o Japão começou a enviar chinelos de borracha para os EUA como uma de suas primeiras exportações após a guerra. Esses eram comercializados como Zoris (nome dado pelos japoneses), que eram tiras japonesas feitas de palha.

No Brasil, o chinelo teve sua aparição apenas em 1962, pela empresa Alpargatas, a Havaianas (marca dada aos chinelos pela empresa) se tornou a marca mais popular de chinelos do mundo, com mais de 150 milhões de pares sendo produzidos a cada ano. Com estilo no Zori japonês, as pessoas começaram a usar a sandália de borracha o tempo todo, substituindo calçados mais convencionais, como tênis (INDEPENDENT, 2010).

Em um estudo realizado pelo Instituto de Estudos e Marketing Industrial (IEMI) em 2013, analisou que o mercado de chinelos no Brasil representava 50\% do total de calçados produzidos no território nacional, impactando de 6,7 bilhões de reais na economia. Em relação ao mercado internacional, a China lidera a produção com uma representação $54 \%$ da produção mundial, enquanto que o Brasil ocupa a quarta posição com 4,5\% de 20,6 bilhões de pares produzidos em todo o mundo (IEMI, 2016).

Dentro desta abordagem, este cenário competitivo vem obrigando as empresas a promoverem uma grande mudança nos seus processos produtivos e administrativos. Tais mudanças estão subordinadas a práticas que proporcionam a redução de custos de fabricação e extinguir desperdícios, permitindo as organizações estabelecerem preços competitivos aos da concorrência, entrevendo a continuidade de suas operações (MÜLLER,2007). 


\subsection{Manufatura enxuta}

O Lean Manufacturing, também conhecido como manufatura enxuta, é a filosofia que utiliza algumas técnicas e práticas que são inseridas nas organizações a fim de modificar e estruturar o sistema produtivo à realidade atual. É uma filosofia operacional criada no Japão pós Segunda Guerra Mundial, pelo Engenheiro da Toyota Taiichi Ohno, e seus precursores. Modelo que ficou conhecido como Sistema Toyota de Produção e onde posteriormente passara a ser conhecido como Manufatura Enxuta. Tal modelo desenvolve a necessidade de tornar a produção mais eficiente, ou seja, de acordo com Bhasin e Burcher (2006), como uma opção contra intuitiva ao sistema vigente, a produção em massa.

Estima-se que o termo Lean (enxuto) foi escrito pela primeira vez em 1990 no livro "A máquina que mudou o mundo", relatando que a implementação de programas de melhorias e práticas gerenciais contribuíram muito na competividade entre as companhias do segmento de automotivo, líderes de mercado da época. A mentalidade enxuta nada mais é do que especificar valor, alinhar as atividades que agregam valor ao produto ou serviço da melhor maneira possível, executando-as sempre e buscando o seu aperfeiçoamento (WOMACK e JONES, 1998).

Em termos mais simples, segundo Azevedo, Barros Neto e Nunes (2010), a manufatura enxuta tem como seus principais objetivos eliminar ao máximo as perdas e os desperdícios gerados em todo processo e qualquer área da produção, inclusive no relacionamento com os clientes, projeções de produtos, estoques baixos, cadeia de fornecedores, e a gestão fabril, atendendo as necessidades dos clientes exatamente como eles desejam e no tempo correto.

De acordo com Ohno (1997), diante das atuais condições estratégicas impostas pelo mercado, os maiores desperdícios de uma indústria concentram-se na produção e, portanto, as estratégias de negócio das organizações devem considerar que tornando eficiente qualquer atividade relacionada a manufatura, podem gerar vantagens competitivas.

A manufatura enxuta é um sistema de gestão focada na redução de sete tipos de desperdícios. São eles: superprodução, espera, transporte, excesso de processamento, inventário, movimento e defeitos. O sistema objetiva aumentar a eficiência da produção pela eliminação contínua de desperdícios (LIKER, 2005).

Para uma implementação eficiente e de sucesso desta metodologia, é preciso que todas as partes interessadas no processo de produção estejam comprometidas e preparadas para tal mentalidade. Para a identificação e medição destas melhorias são utilizados alguns métodos e ferramentas que possibilitarão a redução de estoque, aumento de produtividade e qualidade nos 
produtos fabricados. (OHNO, 1997). No quadro 1 segue algumas aplicações utilizadas para tal Sistema:

Quadro 1 - Competências técnicas e ferramentas para implementação do Lean Manufacturing

\begin{tabular}{|c|c|}
\hline Ferramentas & Funcionalidade \\
\hline Mentalidade Enxuta & $\begin{array}{l}\text { A produção Lean segundo o pesquisador do IMVP John Krafcik } \\
\text { (1988) é "enxuta", devido utilizar menos recursos em } \\
\text { comparação a produção em larga escala, menor esforço humano, } \\
\text { menos defeitos, menor espaço utilizado na fábrica, menor } \\
\text { investimento de capital (algumas das fábricas mais eficientes } \\
\text { eram, também, as menos automatizadas), menor tempo gasto e } \\
\text { em um volume mais baixo por tipo de produto (em linhas de } \\
\text { modelos mistos). Além disso, é necessário manter-se longe da } \\
\text { metade do recurso necessário, menos defeitos e produzir uma } \\
\text { variedade cada vez maior de produtos. A produção enxuta, por } \\
\text { outro lado, concentra-se explicitamente na excelência: custos em } \\
\text { declinio contínuo, zero defeitos, zero estoques e variedade } \\
\text { infinita de produtos. }\end{array}$ \\
\hline VSM & $\begin{array}{l}\text { Os mapas de fluxo de valor oferecem uma visão abrangente de } \\
\text { como o trabalho flui através de sistemas integrados e diferem dos } \\
\text { mapas de processos de várias maneiras significativas. Usada no } \\
\text { auxílio a identificar e eliminar com os desperdicios no fluxo de } \\
\text { material e dados de toda empresa. (TAPPING e SHUKER } \\
\text { (2010). }\end{array}$ \\
\hline Kanban & $\begin{array}{l}\text { O conceito do Kanban monitorar o controle de produção. Tem } \\
\text { como função o controle visual, por meio de sinalizações que tem } \\
\text { o objetivo de impulsionar a produção, por meio de cartões } \\
\text { Kanban, painéis, quadros de sinalizações que tem por finalidade } \\
\text { indicar a movimentação e consumo dos produtos. A ferramenta } \\
\text { Kanban tem como finalidade de informar primeiro o funcionário, } \\
\text { que produzem as peças, se essas se fazem necessárias. (Moura, } \\
2003 \text { ) }\end{array}$ \\
\hline Kaizen & $\begin{array}{l}\text { O processo de melhoria contínua pode ser incrementado nas } \\
\text { empresas através do Kaizen (WOMACK et al., 1992). Imai } \\
\text { (1992) e Watanabe (1996) indicam que a ferramenta Kaizen } \\
\text { indica aprimoramento contínuo de serviços, métodos e produtos, } \\
\text { e, que abrange os funcionários diretores, operação e toda a } \\
\text { empresa como um todo. Segundo os autores argumentam os } \\
\text { aperfeiçoamentos continuos produzem uma maior produtividade } \\
\text { do que amplas e repetidas modificações. }\end{array}$ \\
\hline $5 \mathrm{~S}$ & $\begin{array}{l}\text { Surgiu na década de } 50 \text { no Japão a ferramenta } 5 \mathrm{~S} \text { - seiri, seiton, } \\
\text { seiso, seiketsu e shitsuke - que traduzidas como senso de } \\
\text { utilização, organização, limpeza, padronização e disciplina } \\
\text { (UMEDA, 1997), é de grande importância dentro das } \\
\text { organizações que buscam trabalho com qualidade, que prezam a } \\
\text { satisfação do cliente e o bem-estar dos funcionários. Nos } \\
\text { principais objetivos propostos podem-se destacar um ambiente } \\
\text { limpo e organizado, melhor utilização dos recursos, com maior } \\
\text { qualidade no produto final e motivação aos colaboradores na } \\
\text { execução de suas atividades. }\end{array}$ \\
\hline
\end{tabular}




\subsection{Competências técnicas e sociocomportamental}

Uma das maneiras de adequar-se ao cenário competitivo em que as empresas estão inseridas, é o aperfeiçoamento permanente da empresa, envolvendo todos os colaboradores, conscientizando-os de que somente pelo esforço conjunto de cada um é que a empresa sobreviverá e manter os progressos conquistados.

De acordo com o Lean Institute Brasil, tal aperfeiçoamento e mudança de cultura em todo âmbito organizacional segue em linha com a avaliação da mentalidade e competências dos colaboradores. As competências técnicas e metodológicas não são mais suficientes, precisando ser complementadas pelas competências sociais, que passam muitas vezes a exercer papel chave em todas as relações humanas. O termo competência está presente no ambiente organizacional desde o início da década de 70 (FLEURY; FLEURY, 2000).

Segundo Pavez e Alárcon (2012), competência técnicas engloba as teorias, conceito, regras, ferramentas, métodos e tecnologias que as pessoas utilizam para conduzir o seu trabalho e solucionar problemas de atividades profissionais. Já a competência sociocomportamental é a habilidade de influenciar as pessoas a se moverem para o cenário de desempenho desejado. Possibilita o desenvolvimento da organização informal de maneira adequada, de forma a concentrar e aproveitar as conversas que a organização produz. É um elemento primordial para formação de equipes de alta performance e conquista mais relevância pois quanto maior a posição, melhor a hierarquia.

\section{Metodologia}

A metodologia considerada para atingir o objetivo proposto com a realização deste trabalho está apresentada na Figura 1.

Figura 1 - Metodologia de pesquisa.

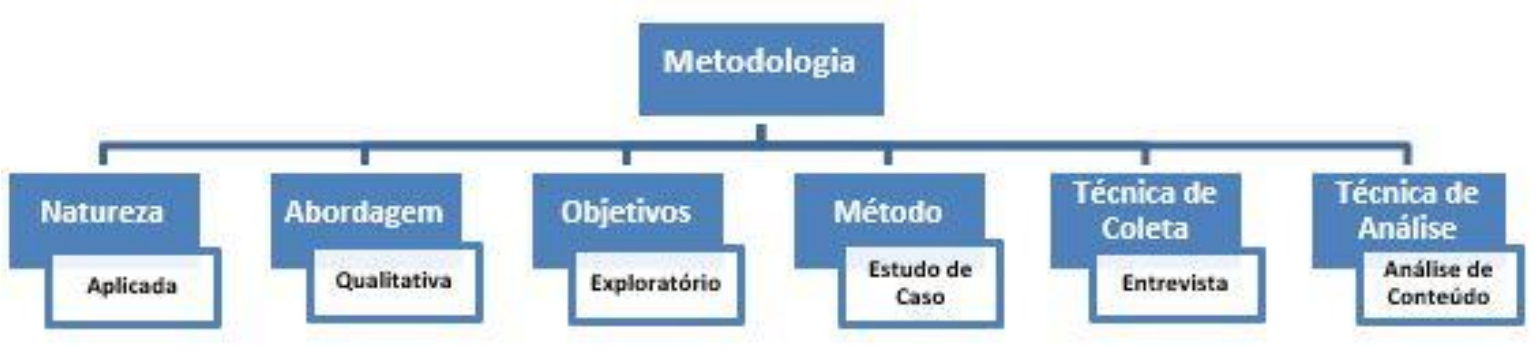

Fonte: Elaborado pelos autores (2020). 
Quanto ao método, foi realizado um estudo de caso que, segundo Nakano (2012), é uma pesquisa sem estruturação formal do método de pesquisa. Para Yin (2010), o estudo de caso é um estudo empírico que avalia acontecimentos atuais na conjuntura da vida real.

Para a coleta de dados realizou-se uma entrevista, que para Marconi e Lakatos (2010), é um encontro entre duas pessoas a fim de que uma delas obtenha informações a respeito de determinado assunto, mediante uma conversação de natureza profissional.

Para avaliar as competências técnicas relacionadas a implementação do Lean Manufacturing, foram estabelecidas as seguintes categorias apresentadas no quadro 2 :

Quadro 2 - Competências técnicas relacionadas a implantação do Lean-Manufacturing.

\begin{tabular}{|c|l|}
\hline Categorias & \multicolumn{1}{|c|}{ Descrições } \\
\hline Lean-Manufacturing & $\begin{array}{l}\text { Esta categoria permite avaliar se os colaboradores sabem identificar custos, } \\
\text { desperdicios, deslocamentos desnecessários e previsibilidade em gestão do tempo. }\end{array}$ \\
\hline Mapa de fluxo de Valor & $\begin{array}{l}\text { Esta categoria permite avaliar se os colaboradores compreendem as rotas dos } \\
\text { procedimentos existentes, padronizam as atividades e otimizam o tempo de ciclo. }\end{array}$ \\
\hline Kanban & $\begin{array}{l}\text { Esta categoria permite avaliar se os colaboradores possuem no ambiente de trabalho: o } \\
\text { controle visual das tarefas, controle dos materiais e o fluxo de trabalho }\end{array}$ \\
\hline Kaizen & $\begin{array}{l}\text { Esta categoria permite avaliar se os colaboradores melhoram continuamente as suas } \\
\text { tarefas. }\end{array}$ \\
\hline 5 "S" & $\begin{array}{l}\text { Esta categoria permite avaliar se os colaboradores praticam o 5"S" para manterem o } \\
\text { local de trabalho sempre limpo, padronizado e organizado. }\end{array}$ \\
\hline
\end{tabular}

Fonte: Adaptado de FRANZINI FILHO et. Al (2019).

Para avaliar as competências comportamentais relacionadas a implementação do Lean Manufacturing, foram estabelecidas as seguintes categorias apresentadas no quadro 3:

Quadro 3 - Competências sociocomportamental relacionadas a implantação do Lean Manufacturing.

\begin{tabular}{|l|l|}
\hline \multicolumn{1}{|c|}{ Categorias } & \multicolumn{1}{c|}{ Descrições } \\
\hline Liderança & $\begin{array}{l}\text { Esta categoria permite avaliar se os colaboradores reconhecem os valores de seus } \\
\text { demais colegas, além de incentivar os mesmos. Também avalia se ele é visto como um } \\
\text { ser seguido e possui os conhecimentos necessários para implementação do Lean- } \\
\text { Manufacturing. }\end{array}$ \\
\hline Comprometimento & $\begin{array}{l}\text { Esta categoria permite avaliar se os colaboradores possuem responsabilidade de seguir o } \\
\text { que lhes foi passado de forma ética e efetiva. }\end{array}$ \\
\hline Perseverança & $\begin{array}{l}\text { Esta categoria permite avaliar se os colaboradores envolvidos buscam atingir suas metas } \\
\text { independentemente dos obstáculos que venham a surgir. }\end{array}$ \\
\hline Organização & $\begin{array}{l}\text { Esta categoria permite avaliar se os colaboradores possuem como objetivo ordenar suas } \\
\text { aditividades, de maneira prática de fácil acesso. }\end{array}$ \\
\hline Disciplina & $\begin{array}{l}\text { Esta categoria permite avaliar se os colaboradores possuem disciplina para realizar suas } \\
\text { tarefas corretamente, criando hábito e mudando a cultura da organização. }\end{array}$ \\
\hline Pró-atividade & $\begin{array}{l}\text { Esta categoria permite avaliar se os colaboradores possuem atitude em suas açoes, } \\
\text { fazendo com que o resultado seja sempre positivo. }\end{array}$ \\
\hline
\end{tabular}


As repostas foram classificadas conforme escala Likert, sendo: (1) discordo totalmente, (2) discordo parcialmente, (3) indiferente, (4) concordo parcialmente e (5) concordo totalmente (CUNHA, 2007). O gráfico radar exibe observações multivariáveis de forma a apresentar a moda amostral de um conjunto de dados trata do valor que ocorre com maior frequência ou o valor mais comum em um conjunto de dados e é especialmente útil quando os valores ou observações não são numéricos, casos em que a média ou mediana não podem ser definidas.

Para medir o grau da correlação entre os princípios em defasagem pelos resultados abordados no gráfico radar, observa-se a matriz onde estão dispostos os coeficientes de correlação de Pearson que assumem valores entre -1 e 1, onde:

- 0.9 para mais ou para menos indica uma correlação muito forte;

- 0.7 a 0.9 positivo ou negativo indica uma correlação forte;

- 0.5 a 0.7 positivo ou negativo indica uma correlação moderada;

- 0.3 a 0.5 positivo ou negativo indica uma correlação fraca;

- 0 a 0.3 positivo ou negativo indica uma correlação desprezível. 
Calcula-se o coeficiente de correlação de Pearson segundo a seguinte fórmula:

$$
\rho=\frac{\sum_{i=1}^{n}\left(x_{i}-\bar{x}\right)\left(y_{i}-\bar{y}\right)}{\sqrt{\sum_{i=1}^{n}\left(x_{i}-\bar{x}\right)^{2}} \cdot \sqrt{\sum_{i=1}^{n}\left(y_{i}-\bar{y}\right)^{2}}}=\frac{\operatorname{cov}(X, Y)}{\sqrt{\operatorname{var}(X) \cdot \operatorname{var}(Y)}}
$$

Onde são os $x_{1}, x_{2}, \ldots, x_{n}$ e $y_{1}, y_{2}, \ldots, y_{n}$ valores medidos de ambas as variáveis.

$$
\begin{aligned}
& \bar{x}=\frac{1}{n} \cdot \sum_{i=1}^{n} x_{i} \text { (2) } \mathrm{e}^{\bar{y}=\frac{1}{n} \cdot \sum_{i=1}^{n} y_{i}} \text { (3) são as médias aritméticas de } \\
& \text { Além disso, }
\end{aligned}
$$
ambas as variáveis.

A técnica para análise dos dados coletados é a de análise de conteúdo. Bardin (1977) ressalta a importância do rigor na utilização da análise de conteúdo, a necessidade de ultrapassar as incertezas e descobrir o que é questionado. Por meio da análise categorial, que, conforme Bardin (2011), consiste no desmembramento do texto em categoriais agrupadas analogicamente, há o respaldo no fato de que é a melhor alternativa quando se quer estudar valores, opiniões, atitudes e crenças, através de dados qualitativos. Portanto, a interpretação dos dados se deu pelo método análise de conteúdo, respaldada pelas observações in loco. As etapas da técnica orientadas por Bardin (2011). Essas etapas são organizadas em três fases: 1) pré-análise, 2) exploração do material e 3) tratamento dos resultados, inferência e interpretação.

\section{Análise e discussão dos resultados.}

A empresa objeto de estudo é a Kuatro Kantos, uma empresa de pequeno porte de caráter familiar, situada na região Leste da cidade de São Paulo. Fundada no ano de 2012, a empresa está há 8 anos no mercado de atacado e varejo, buscando atender e garantir a inovação de seus produtos. A Kuatro Kantos atua no ramo de calçados, especializada na fabricação e comercialização especificamente de chinelos emborrachados com formato "retangular". Atualmente a empresa conta com um espaço de $500 \mathrm{~m}^{2}$ e 20 colaboradores, sendo 13 situados na produção dos chinelos e 7 estão divididos na área administrativa e comercial.

Observa-se o processo de fabricação de chinelos na Figura 2. Inicia-se pelo recebimento da matéria-prima (borracha), seguido do corte da borracha, formar a fresa lateral e por fim inserir as correias e realizar o acabamento do produto. Quando há necessidade de 
personalização conforme solicitação do cliente, inclui-se uma última etapa de estamparia no chinelo.

Figura 2 - Fluxograma de representação do processo de fabricação de chinelo.

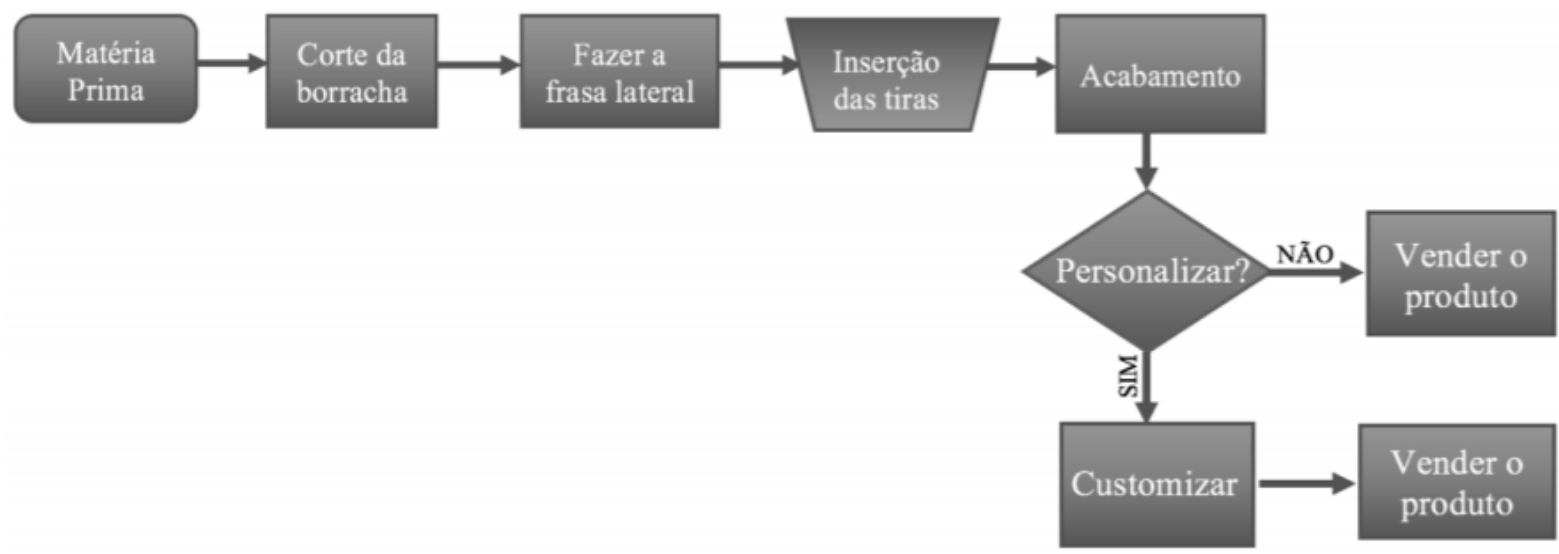

Fonte: Elaborado pelos autores (2020).

Para atingir ao objetivo proposto por este trabalho, realizou-se um estudo de caso a no primeiro semestre de 2020. Os dados foram coletados a partir de entrevistas semiestruturadas aplicadas aos 20 colaboradores da organização. e suas respostas no que diz respeito a capacidade de implementação da filosofia Lean Manufacturing e suas ferramentas através de suas competências técnicas e sociocomportamentais.

A percepção dos respondentes quanto as competências sociocomportamentais relacionadas a implantação do Lean-Manufacturing estão ilustradas na Figura 3:

Figura 3 - Gráfico radar para as competências sociocomportamentais.

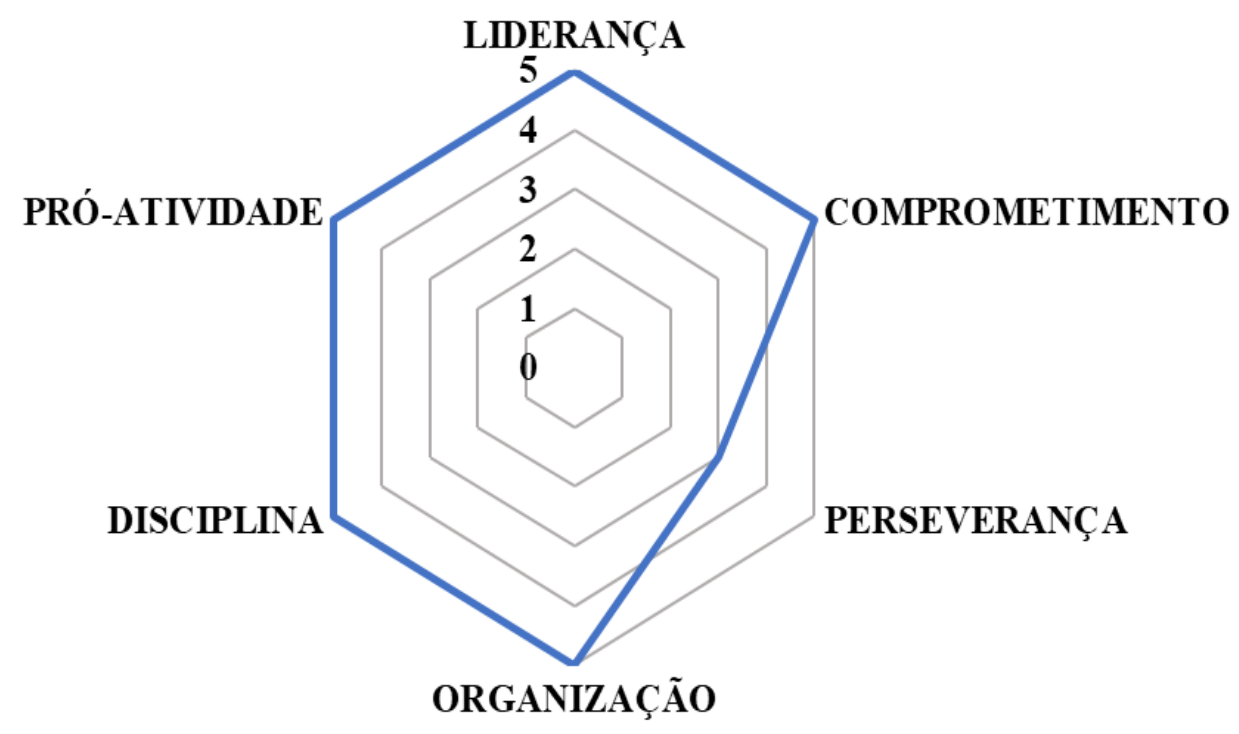

Fonte: Elaborado pelos autores (2020). 
Observa-se que os respondentes se consideram exemplos de organização, limpeza e costumam incentivar seus colegas. Dessa forma, a liderança é uma competência comportamental positiva entre os respondentes. Quanto a competência comportamental comprometimento, os respondentes consideram-se responsáveis pela organização e limpeza no seu ambiente de trabalho.

Os respondentes também afirmaram em sua maioria (90\%) que mantêm seu ambiente de trabalho organizado e os objetos e utensílios são facilmente localizados. Dessa forma, observa-se a organização como uma competência positiva entre os respondentes.

Quanto a disciplina dos colaboradores, mostraram-se competentes, realizando as atividades de forma correta e colaborando para o ambiente da organização. Outra categoria avaliada foi a pró-atividade, em que majoritariamente, os respondentes consideram- se proativos na resolução de problemas relacionados a organização e limpeza em seu ambiente de trabalho.

A perseverança é o aspecto com a avaliação menos positiva entre os colaboradores. Observa-se que os funcionários da empresa buscam atingir as metas para a eliminação de desperdícios, porém afirmar ter dificuldades para transpor os obstáculos que venham a surgir durante os processos e em todo âmbito organizacional.

A percepção dos respondentes quanto as competências técnicas relacionadas a implantação do Lean-Manufacturing estão demonstradas na Figura 4: 


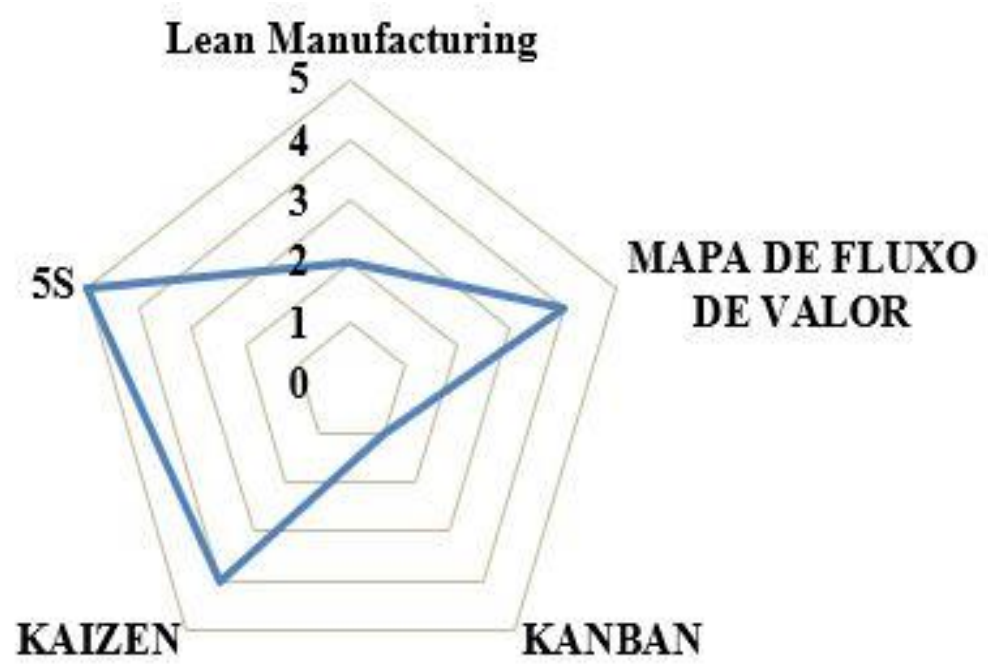

Fonte: Elaborado pelos autores (2020)

Quanto as competências técnicas, observa-se uma maior defasagem entre as categorias abordadas aos colaboradores. Em relação aos conhecimentos e práticas dos questionamentos sobre Mapa de Fluxo de Valor, Kaizen e metodologia 5S, apresentaram bons conhecimentos e bom desempenho. Tendo em vista o que fora discutido, os colaboradores entendem quais atividades que agregam valor e quais podem ser dispensadas, mantendo seu local de trabalho limpo, organizado, além de compreenderem os processos existentes, otimizando seu tempo de trabalho e buscando a melhoria contínua em suas atividades.

Em contrapartida, os colaboradores não demonstraram conhecimentos em relação aos conceitos da metodologia Lean Manufacturing e o uso da metodologia Kanban, ou seja, a organização não identifica com facilidade tópicos como custos, desperdícios, deslocamentos desnecessários e previsões, além de não demonstrarem um controle visual eficiente das tarefas, controle dos materiais de produção e fluxo de trabalho.

O grau da correlação entre as competências técnicas e sociocomportamentais está apresentado no Quadro 4. Para esta análise foram consideradas as competências com menor avaliação positiva entre os colaboradores: perseverança (competência comportamental), Lean e Kanban (competências técnicas). As questões aplicadas aos colaboradores entrevistados durante as entrevistas para estas competências estão disponíveis no Apêndice A.

As competências técnicas e comportamentais avaliadas de forma positiva entre os colaboradores entrevistados não foram consideradas para esta análise correlacional. 
Quadro 4 - Matriz de correlação das competências técnicas e sociocomportamentais

\begin{tabular}{|c|c|c|c|}
\hline \multirow{2}{*}{\multicolumn{2}{|c|}{$\begin{array}{c}\text { Correlação entre competências técnicas } \\
\text { e sociocomportamentais }\end{array}$}} & \multicolumn{2}{|c|}{ PERSEVERANÇA } \\
\hline & & \multirow{2}{*}{ 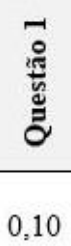 } & \multirow{2}{*}{ 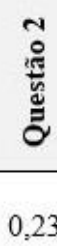 } \\
\hline \multirow{2}{*}{ LEAN } & Questão 1 & & \\
\hline & Questão 2 & 0,54 & 0,45 \\
\hline \multirow{2}{*}{ KANBAN } & Questão 1 & 0,04 & 0,40 \\
\hline & Questão 2 & 0,32 & 0,31 \\
\hline
\end{tabular}

Fonte: Elaborado pelos autores. (2020)

Considerando os coeficientes de Pearson para esta análise correlacional, seguem as principais considerações:

- a primeira correlação entre Lean e perseverança apresenta-se fraca/desprezível (0.10 e 0.23), o que significa que não relação entre metas de eliminação de desperdícios e estoque de materiais de acordo com as respostas obtidas junto aos colaboradores respondentes;

- a segunda correlação entre Lean e perseverança apresenta-se moderada (0.54 e 0.45$)$, o que demostra que a organização e limpeza contribuem na redução de desperdícios;

- a primeira correlação entre Kanban e perseverança apresenta-se fraca (0.40), o que pode sugerir que a falta de indicadores visuais pode contribuir com desperdício.

- a segunda correlação Kanban e perseverança apontam correlação desprezível (0.32 e 0.31), não identificando uma conexão entre organização e limpeza do ambiente com o controle de entrada e saída de material.

Portanto, o Kanban apresenta-se como uma das competências técnicas ausentes de acordo com quase todos os respondentes em razão da falta de controle visual para consumo e reposição dos materiais de produção, além da ausência de fluxo de realização de serviços nos seus ambientes de trabalho. Após análise do processo produtivo de chinelos, observa-se maior dificuldade para o controle do consumo e reposição da matéria-prima (borracha). Desta forma, recomenda- se a implementação do Kanban neste ambiente de produção da organização. Propõe-se a utilização de cartões em um quadro para indicar e acompanhar, de maneira visual, prática e utilizando poucos recursos, o andamento dos fluxos de produção na empresa. 
Ficou evidenciado um conhecimento limitado entre os colaboradores sobre os conceitos Lean Manufacturing, o que sugere aos líderes da produção, planejarem a mudança de cultura dos colaboradores, implementando a mentalidade enxuta para avaliação dos

processos. É importante ressaltar que os colaboradores possuem um papel fundamental na redução dos desperdícios, pois cabem a eles o papel de transformar os planos em ações práticas.

\section{Considerações finais.}

O objetivo do presente artigo foi analisar as percepções dos colaboradores sobre a implantação do Lean-Manufacturing na empresa Kuatro Kantos. Como resultado desta análise, conclui-se que as competências comportamentais se sobrepõem às competências técnicas na avaliação de implantação do Lean Manufacturing. Em linhas gerais, observou-se que a organização e limpeza são praticadas na organização na opinião dos colaboradores respondentes. Para as competências comportamentais, destaca-se entre os respondentes: a liderança, o comprometimento, a organização, a disciplina e a proatividade. Entre as competências sociocomportamentais com menor aderência, observa-se a perseverança, em razão da dificuldade em superar obstáculos. Sobre as competências técnicas, observa-se como pontos fortes entre os respondentes: o 5S, Kaizen e mapa do fluxo de valor e os pontos fracos apresentam-se para as ferramentas/metodologias Kanban, e Lean Manufacturing.

As limitações para a realização deste trabalho apresentam-se em razão de tratar-se de um estudo transversal, ou seja, para um melhor entendimento, deveria ser aplicado um estudo longitudinal (antes-e-depois). Outra limitação relevante, as entrevistas foram realizadas em uma única empresa fabricante de chinelos, não podendo os resultados serem generalizados para outros processos de fabricação de chinelos.

Espera-se que as informações providas por este trabalho contribuam com a futura implantação das ferramentas de menor conhecimento na empresa e principalmente a evolução contínua de todas as competências sociocomportamentais. Por se tratar de um tema relevante, espera-se que os dados apurados também possam motivar outros pesquisadores e os próprios stakeholders da organização a analisar a implantação do Lean Manufacturing em todos os processos. 
Sugere-se como realização de pesquisas futuras, pesquisas específicas para as competências técnicas relacionadas a implantação do Lean Manufacturing com baixa aderência entre os respondentes: ao Kanban, Lean.

\section{Agradecimentos}

Os agradecimentos à Instituição de Ensino Superior (IES) pelo apoio e incentivo a pesquisa, seu corpo docente, administração e coordenação do curso de Engenharia de Produção.

\section{REFERÊNCIAS}

AZEVEDO, M. J.; BARROS NETO, J.P.; NUNES, F. R. M. Análise dos aspectos estratégicos da implantação da Lean Construction em duas empresas de construção civil de Fortaleza-CE. In: SIMPÓSIO DE ADMINISTRAÇÃO DA PRODUÇÃO, LOGÍSTICA E OPERAÇÕES INTERNACIONAIS, 13., 2010, São Paulo. Anais... São Paulo: Escola de Administração de Empresas de São Paulo, 2010. p. 01-16.

BARDIN L. L'Analyse de contenu. Editora: Presses Universitaires de France, 1977. Análise de conteúdo. SP: Edições 70, 2011.

BHASIN, S.; BURCHER, P. Lean viewed as a philosophy. Journal of Manufacturing Technology Management, Bingley, v. 17, n. 1, p. 56-72, 2006;

CUNHA, Luísa Margarida Antunes da et al. Modelos Rasch e Escalas de Likert e Thurstone na medição de atitudes. 2007.

FLEURY, A. C. C.; FLEURY, M. T. L. Estratégias empresariais e formação de competências. São Paulo: Atlas, 2000;

FRANZINI FILHO, Carlo Roberto et al. Análise da percepção dos colaboradores sobre a implantação do Lean Office nas organizações. In: XV Encontro Mineiro de Engenharia de Produção (EMEP), 2019, Viçosa-MG. Anais. Minas Gerais, 2019. Disponível em: < http://www.fmepro.org/ojs/index.php/aem/issue/view/20> Acesso em: 24 mar. 2020.

HAVAIANAS. The real stories: Bringing joy to your feet since '62. Disponível em: <https://www.havaianas-store.com/pt/historia> Acesso em: 20 abr. 2020;

HINES, Peter. Value Stream Management: Strategy and Excellence in the Supply Chain. Financial Times/Prentice Hall, Harlow: 2000;

IMAI, M. Kaizen: a Estratégia para o Sucesso Competitivo. $5^{\text {a }}$ ed. São Paulo: IMAM, 1994, p. 236;

INDEPENDENT. INDY/LIFE: First steps, 4,000 BC. Disponível em: $<$ https://www.independent.co.uk/life-style/fashion/features/the-timeline-flip-flops2039012.html> Acesso em: 20 mar. 2020; 
LEAN INSTITUTE DO BRASIL. Lean Enterprise: a gestão enxuta em busca da excelência. Disponível em: <https://www.lean.org.br> Acesso em: 18 mar. 2020;

LIKER, J. K. O modelo Toyota: 14 princípios de gestão do maior fabricante do mundo. Porto Alegre: Bookman, 2005;

MARCONI, M. De A.; LAKATOS, E. M. Técnicas de pesquisa. São Paulo: Atlas, 2007.

MÜLLER, Roger Mário. Integração do Método SMED ao Método de Custeio ABC no Diagnóstico de Prioridades de Melhorias nas Operações de Sentup. Curitiba/PR: Dissertação de Mestrado, Universidade Federal do Paraná, 2007;

NAKANO, D. Métodos de pesquisa adotados na Engenharia de Produção e gestão de operações. In: MIGUEL, P.A.C. (Coord.). Metodologia de pesquisa em Engenharia de Produção e Gestão de Operações. 2. ed. São Paulo: Elsevier, 2012.

OHNO, T. O Sistema Toyota de Produção: além da produção em larga escala. 1 ed. Porto Alegre: Artes Médicas, 1997;

PAVEZ, Ignácio \& ALARCON, Luis. The Lean Construction Professional Profile (LCPP): Implementation in Chilean Contractor Organizations. Global Perspective on Engineering Management. 1. 59-66. 2012;

SEBRAE. Mercado de chinelos no brasil e as oportunidades para o mundial: Kuatro Kantos Inca. Disponível em: <https://www.sebrae2014.com.br> Acesso em: 17 abr. 2020;

SLACK, N. Vantagem competitiva em manufatura - Atingindo competitividade nas operações industriais. São Paulo, Atlas, 2002.

TAPPING, D.; SHUKER, T. Lean Office: Gerenciamento do Fluxo de Valor para Áreas Administrativas - 8 passos para planejar, mapear e sustentar melhorias Lean nas áreas administrativas. São Paulo: Leopardo Editora, 2010;

TRANSPARENCY MARKET RESEARCH. Flip Flops Market - Global Industry Analysis, Size, Share, Growth, Trends, and Forecast 2018 - 2026: Flip Flops Market - Overview. Disponível em: <https://www.transparencymarketresearch.com/flip-flops-market.html> Acesso em: 20 mar. 2020;

WATANABE, S. O modelo japonês: sua evolução e transferibilidade. Revista da Administração. São Paulo, v. 31, n.3, p. 5-18. jul./set. 1996;

WOMACK, J.; JONES, D. A mentalidade enxuta nas empresas: elimine o desperdício e crie riqueza. 5 ed. Rio de Janeiro; Campus, 1998.427p.

YIN, R. K. Estudo de caso - Planejamento e Métodos. 4ª ed. Porto Alegre: Bookman, 2010. 


\section{APÊNDICE A - Questões para análise de competências}

- Competência Perseverança:

Questão 1- O meu ambiente de trabalho possui metas e estas são cumpridas para a eliminação de desperdicios.

Questão 2- Tenho dificuldade em superar os obstáculos.

- Competência Lean Manufacturing:

Questão 1- Altos estoques de material em processamento e acabado são vistos como uma segurança de que não faltará matéria-prima para o processo seguinte, nem produto para o cliente

Questão 2- Acredito que há desperdício de recursos no meu ambiente de trabalho.

- Competência Kanban:

Questão 1- No meu ambiente de trabalho existe controle visual para o consumo e reposição dos materiais

Questão 2- No meu ambiente de trabalho existe controle visual para a execução dos serviços (entrada e saída). 